\title{
Environmental Impact of Technologies
}

${ }^{* 1}$ Kwazo H.A.

\author{
2Muhammad M.U.
}

3Tafida G.M

\author{
4S. Mohammed \\ 1, 2 and 4 Department of Chemistry, Shehu Shagari College of Education, Sokoto State,Nigeria \\ ${ }^{3}$ Department of Biology, Adamu Augie College of Education, Argungu, Kebbi State, Nigeria
}

Doi:10.5901/ajis.2014.v3n7p83

\section{Abstract}

Technologies used within our environment are important aspect of our life; however, their environmental impacts are often not realized or considered. These impacts are expressed throughout the manufacturing, use and disposal of these products within our environmental premises and thus require monitoring and an understanding of each stage of technological life cycle. These technological accessories and machineries are located in our homes, offices, hospitals, schools (universities and colleges), laboratories, libraries, farms and every other place in our environmental premises, such technological accessories and machineries consumes various quantities of energy, but as a whole are not operating at optimal efficiency. The inefficient use and disposal of these technological by-products within our environment do not occur in the most environmentally sound manner possible, thus resulting in diverting unwanted places to landfills or storing them for extended periods of time. Both the inefficient use, manufacturing and disposal leads to generation and release of toxic compounds into the environment. Most organizations and industries begin their efforts to decrease technological waste and minimize their environmental impact by tackling small and focused problems. For example, there are chlorinated plastics in cable wiring, lead in cathode ray tube (CRT) monitors, brominated flame retardants in computers, and mercury in LCD displays. This paper identified the needs for the implementation of environmental-wide green procurement strategies with respect to technology acquisition, use and disposal, as well as, offers recommendations regarding improvement of our environmental current systems.

Keywords: Environment, Impacts, Technologies, Strategies and Implementation.

\section{Introduction}

The effects of technologies underline early twenty-first century global challenges. On the one hand, since the enlightenment, technology, especially science-based technology, has offered the promise of a better world through the elimination of disease and material improvements to standard of living. On the other hand, resource extraction, emission of dangerous materials, and pollution of air, water and soil have created conditions for unprecedented environmental catastrophe and have already caused irreversible damage to the biosphere. While the future might promise a vast acceleration of technological innovation, the scale and impact of environmental degradation may reflect this vast acceleration as well (UNEP, 2013). Technologies have affected society and its surroundings including the environment in a number of ways. In many societies, technologies have helped develop more advanced environmental problems including global warming. Many technological processes produce unwanted by-products, known as pollution and deplete natural resources, to the detriment of Earth's environment. Various implementations of technologies influence the values of a society and new technologies often raises new ethnical questions (WHO, 2013).

\section{Environment}

Environment is the sum total of all conditions and influences that affect the development and life of all organisms on earth. The living organisms vary from the lowest micro-organisms such as bacteria, virus, fungus, etc. to the highest, including man. Each organism has its own environment. The word "environment" can mean many things to many people. 
Some consider it to be preservation of a scenic natural landscape or dwindling wildlife species. According to some, it is industrial pollution or threat to citizens' amenities caused by the building of a road or a big factory. Others may treat it as the mother of natural resources-energy, land, water, atmosphere and minerals (Anil and Arnab, 2001). The natural environment comprises all natural occurring surroundings and conditions in which living things grow and interact on Earth. These include complete landscape units that function as natural systems without major human intervention occurring within their boundaries. They also include universal natural resources that lack clear-cut boundaries such as; air, water and climate. Environment (Biophysical) refers to the physical and biological factors along with their chemical interactions that affect an organism where pollution is important. Knowledge environment include; social practices, technological and physical arrangements invented to facilitate collaborative knowledge building, decision making, inference or discovery (Anil and Arnab, 2001).

\section{Environmental-wide Green Procurement}

Green procurement is the integration of environmental performance considerations into the procurement process. Goods and services are considered green when they have a lesser or reduced effect on human health and the environment than competing goods or services that serve the same purpose (Canada, 2005). Environmental-wide green procurement is the purchase of goods and services that are less harmful to the environment and to human health than competing products and services that serve the same purpose (Canada, 2005). It includes the following;

- Looking at how needs could be met without new purchasing.

- Choosing a manufacturer who can demonstrate good environmental management practices; and

- Buying goods that are produced with fewer resources, do not use or release toxic substances, are energy efficient, or are easily disassembled for reuse and recycling.

\section{Technology}

Technology is the making, modification, usage and knowledge of tools, machines, techniques, crafts, systems and methods of organization, in order to solve a problem, improve a pre-existing solution to a problem, achieve a goal, handle an applied input/output relation or perform a specific function. It can also refer to the collection of such tools, including machinery, modifications, arrangements and procedures. Technologies significantly affect humans as well as other animal's species ability to control and adapt to their natural environments (Hassan et al., 2013). Example of technologies includes; construction technology, medical/health technology, biotechnology, green technology, nanotechnology and Information Communication technology (ICT) etc.

Construction technology: It Covers the basic elements of substructure (site works, settings out and foundations) and superstructure (flooring and roofs, simple finishes, fittings and fixtures) as well as basic services such as water, gas electricity and drainage, and considers low-rise framed industrial and commercial buildings. Throughout the world, construction technology is responsible for high levels of pollution as a result of the energy consumed during extraction, processing and transportation of raw materials (Adalbert, 1996).

Medical /Health Technology: It refers to any intervention that may be used for safe and effective prevention, diagnosis, treatment and rehabilitation of illness and diseases (WHO, 2013). This includes the pharmaceuticals, devices, procedures and organizational systems used in health care (INAHTA, 2009). Medical technology is a proper subset of health technology, encompasses a wide range of healthcare products and is used to diagnose, monitor or treat diseases or medical conditions affecting humans (ADVAMED, 2009). Health care as a sector is a major user of energy and generator of waste. Many institutions are taking steps to curb their energy consumption, reduce waste, and design processes and facilities that are more environmentally friendly and, as a result, healthier. Health care as an industry contributes significantly to environmental problems and that environmental problems, especially climate change, contribute significantly to health problems. As a result of this understanding, health care facilities have begun to implement programs and policies that minimize the impact of their activities on the environment (Jeanette and Carl, 2011).

Agricultural technology: Is the application of techniques to control the growth and harvesting of plants and animals products. It refers to agricultural machinery that is used in the operation of an agricultural area or farm. Agricultural technology focuses on technological processes used in agriculture, to create an understanding of how processes, equipment and structures are used with people, soil, plants, animals and their products, to sustain and maintain quality of life and to promote economic, aesthetic and sound cultural values. Agriculture is facing the challenge 
of feeding an increasing global population while natural resources are shrinking due to a combination of factors. Many feel that biotech crops can contribute to meeting global food needs by improving agricultural productivity. Yet, the potential risks associated with the cultivation of biotech crops should be accurately evaluated and managed. The base line in evaluating those risks should be a good knowledge of the impacts and foot prints of the current agricultural systems. Current practices such as tillage, water use, intercropping, crop rotation, grazing and extensive usage of pesticides affect the biodiversity of agricultural fields as well as the environment outside of fields. The undesirable effects of modern agriculture on the environment have been widely publicized. The extent to which the undesirable impact can be minimized by intensive use of available science and technology on the most suitable land of great significance but has been generally overlooked (Aldrich, 1972).

Biotechnology: Is the use of any technique that makes use of biological systems, living organisms or their derivatives to develop, make or modify useful products, to improve plants or animals, or to develop micro-organisms for specific purposes (NABDA, 2002). The American Chemical Society defines biotechnology as the application of biological organisms, systems, or processes by various industries to learning about the science of life and the improvement of the value of materials and organisms such as pharmaceuticals, crops and livestock. In other words, biotechnology can be defined as the mere application of technical advances in life science to develop commercial products. Biotechnology is cutting edge technology with the following applications; food and agricultural biotechnology, medical biotechnology, environmental biotechnology as well as industrial biotechnology (Obasanjo Reforms on Biotechnology, 2006). For the most plant, crops developed with biotechnology will have many impacts on the environment. Benefits include reduced pesticides used, improved water and soil conservation and greater safety for workers and the ecosystems. Likewise, potential risks from biotech crops are similar to those we face with plants developed by traditional methods. Environmental biotechnology more efficiently cleans up many hazardous wastes than conventional methods and greatly reduces our dependence for waste cleanup on methods such as incineration of hazardous waste dump sites. Ecological impact of biotechnology (agricultural) include; spreading genetically engineered genes to indigenous plants, increasing toxicity, which may move through the food chain, disrupting nature system of pest control, creating new weeds or virus strains etc (NABDA, 2002).

Nanotechnology: Is the engineering of functional systems at the molecular scale. It is the manipulation of matter on an atomic, molecular, and supramolecular scale. This covers both current work and concepts that are more advanced (Drexler, 1992). An area of concern is the effect that industrial-scale manufacturing and use of nanomaterials would have on human health and environment, as suggested by nanotoxicology research (CDC-NIOSH Publication, 2014). The environmental impact of nanotechnology is the possible effects that the use of nanotechnological materials and devices will have on the environment. Nanotechnology environmental impacts include; the possible novel type of pollution that nanotechnological materials might cause if released into the environment. Some nanoparticles products may have unintended consequences. Nanopollution is a general name for waste generated by nanodevices or during the nanomaterials manufacturing process. Ecotoxicological impacts of nanoparticles and the potential for bioaccumulation in plants and microorganisms is a subject of current research, as nanoparticles are considered to present novel environmental impacts (Gyory, 2007). Researchers have discovered that bacteriostatic silver nanoparticles used in socks to reduce foot odor are being released in the wash (Lubick, 2008). These particles are often flushed into the waste water stream and may destroy bacteria which are critical components of natural ecosystems, farms, and waste treatment processes.

Environmental technology: Environmental technology (envirotech), green technology (greentech) or clean technology (cleantech) is the application of one or more of environmental science, green chemistry, environmental monitoring and electronic devices to monitor, model and conserve the natural environment and resources, and to curb the negative impacts of human involvement. The term is also used to describe sustainable energy generation technologies such as photovoltaics, wind turbines, bioreactors, etc. Sustainable development is the core of environmental technologies. The term environmental technology is also used to describe a class of electronic devices that can promote sustainable management of resources (Taesler, 1991).

Information Communication technology (ICT): Is the application of computers and telecommunications equipment to store, retrieve, transmit and manipulate data (Daintith, 2009). ICT is universally regarded as essential tools in enhancing environmental problems (such as environmental pollution). Today, it is commonly accepted that; ICTs has significant impacts on the environment. These effects will only be fully realized if, and when, ICT such as computer and mobile phones accessories are widely spread and used which is rampart in the society. Technology and Information Communication Technologies has affected society and its surroundings in a number of ways. In many societies, technology has helped develop more advanced environmental problems including environmental pollution. Many 
technological processes produce unwanted by-products known as pollution, and deplete natural resources, to the detriment of Earth environment. Various implementation of technology influence the values of a society and new technology often raises ethical questions. Environmental technology courses oriented towards producing electronic, electrical or electro technology graduates capable of developing devices and artefacts able to monitor, measure, model and control environmental impact, including monitoring and managing energy generation from renewable sources, and developing novel energy generation technologies.

\section{Conclusion}

As technologies advances, it is important that scientists and regulatory agencies assess the importance of both new and existing technologies for environmental activities; farm workers and consumer safety and for any environmental effects on plants, animals and water systems. Some aspects of the environmental impacts are unique to the technologies and require operational studies to determine the seriousness of the effects and the best mitigation options. This will lead to have a green environment that is more healthy and safe for sustainable development.

\section{Recommendations}

1. All technologies shall be regulated by government.

2. There is need for the implementation of environmental education as a subject in schools and colleges to help students develop the analytical and decisison-making skills so as to make wiser environmentally sound choices regarding the design, adoption, use, and disposal of these technologies.

3. There is need to strengthen young peoples environmental awareness and engage children and youth in environmental issues world wide.

4. There is need to promote environmentally sound practices globally by strictly adhering to green environment.

5. There is need for the implementation of environmental-wide green proceurement startegies with respect to technologies acquisition, use and disposal.

\section{References}

Adalbert K. (1996); Energy demand during the life Cycle of a building. CIB symposium Energy Mass and Flow in the life Cycle of building, Vienna.

ADVAMED (2009); Advanced Medical Technology Association.

Aldrich S.R. (1972); Some effects of Crop-Production Technology on Environmental Quality. BioScience Vol.22, No. 2, pp.90-95. Published by: Oxford University Press.

Anil K.D and Arnab K.D (2001); Environmental Studies, New Age International (P) Limited, Publishers 4835/24, Ansari Road, Daryaganj, New Delhi-110002.

Canada (2005): Report of the Commissioner of the Environment and Sustainable Development, office of the Auditor General.

CDC-NIOSH (2014); "Publication and products, filling the knowledge Gaps for Safe Nanotechnology in the workplace". National Institute for Occupational Safety and Health.

Daintith, John, Ed. (2009); "IT, A dictionary of Physics, Oxford University Press, retrieved 1'st August, 2012.

Drexler, K.E (1992); Nanosystems: Molecular Machinery, Manufacturing, and Computation. New York: John Wiley \& Sons. ISBN 0-47157547-X.

Gyory Scrinis (2007); "Nanotechnology and the Environment: The Nano-Atomic reconstruction of Nature". Chain Reaction 97:23-26.

Hassan H.N, Mohammad D. and Amin H.N (2013); Analysis of Technology effectiveness of Lean Manufacturing using System Dynamics. School of Engineering, Yazd University. P.O.Box 1089, 95, Yazd Iran Received 30th June, 2013 accepted August 2013.

INAHTA (2009); International Network of Agencies for Health Technology Assessment. "HTA glossary".

Jeanette Auguston, M.A., and Carl Patow, M.D (2011); Health Care and the Environment: Local Champions, Global Impact. Clinical and Health Affairs.

Lubick, N. (2008); Silver Socks have cloudy lining. Environmental Science and Technology 42(11): 4133-9.

NABDA (2002); National Biotechnology Development Agency "First-ever, Biotechnolgy Agenda Setting Workshop".

Obasanjo (2006); Obasanjo Reforms on Biotehcnology. A Publication of the Federal Ministry of Information and National Oreintation Production, Publication and Documentation Dept. Radio House, Abuja-Nigeria.

Taesler, R. (1991); Climate and building Energy Management. Energy and Buildings, Vol. 15-16, pp599-608.

UNEP (2013): United Nation Environmental Programme. Technology and the Environment.

WHO (2013); World Health Organization. Technology, Health. Environment and Health. 